Mindfulness manual for people with dementia

\title{
A Mindfulness Programme Manual for People with Dementia
}

Joanne Chan ${ }^{1}$, Anna Churcher Clarke ${ }^{1}$, Lindsay Royan ${ }^{2}$, Joshua Stott $^{1}$ and Aimee Spector ${ }^{1}$

${ }^{1}$ Department of Clinical, Educational and Health Psychology, University College London, UK

${ }^{2}$ North East London NHS Foundation Trust, UK

\section{Corresponding Author:}

Joanne Chan, Department of Clinical, Educational and Health Psychology, University College London, 1-19 Torrington Place, London WC1E 7HB, UK.

Email: joanne.chan.12@ucl.ac.uk 
Mindfulness manual for people with dementia

\begin{abstract}
This article describes a 10-session group-based Mindfulness Programme for people with mild to moderate dementia. It aims to equip people with dementia with skills to manage psychological distress, with support from carers. The Mindfulness Programme was developed through reviews of existing literature, consultation with experts and a focus group with people with dementia. In a randomised controlled feasibility and pilot trial with people with mild to moderate dementia in care homes, it was found to significantly increase quality of life. The manual presented here is designed to be administered flexibly to promote participants' personhood. The protocol is designed for use by therapists with experience in practising mindfulness meditation.
\end{abstract}


Mindfulness manual for people with dementia

\section{Overview}

There are around 36 million people with dementia worldwide (Alzheimer's Disease International, 2013). As dementia progresses, people experience cognitive, affective, behavioural and motor difficulties, associated with reduced quality of life (Finkel, 2000). Mindfulness is defined as a way of paying attention on purpose, in the present moment, and in a non-judgmental manner (Kabat-Zinn, 2013). It emphasises the recognition of one's experience with curiosity, openness and acceptance (Bishop et al., 2004). Theoretically, as people with dementia improve in their awareness of their thoughts, emotions and bodily sensations, this may enhance their ability to regulate emotions and to manage stress, which in turn may improve their psychological wellbeing and quality of life. A systematic review of mindfulness based interventions (MBIs) for people with acquired cognitive impairments (Chan, 2015) found inconclusive evidence for people with mild cognitive impairments and dementia, due to methodological weaknesses in the limited available studies $(n=3)$. However, there is some evidence that the intervention is safe (with no reported adverse events) and that people with dementia can learn mindfulness skills with modifications to meet their cognitive and physical limitations (Lantz, Buchalter, \& McBee, 1997; Litherland \& Robertson, 2014; Wells et al., 2013).

The mindfulness programme manual presented here was developed in a recent single blind, randomised controlled pilot study of a 10-session group-based Mindfulness Programme for people with mild to moderate dementia (MMSE (Folstein, Folstein, \& McHugh, 1975) score of 10-26) in care home settings. Participants had the capacity to consent for themselves, some ability to understand and communicate in English and the ability to see and hear well enough to participate in the group and make use of most materials. They were functionally able to maintain some concentration and remain in a group for 45-60 minutes and had minimal challenging behaviour. Participants were excluded if they 
Mindfulness manual for people with dementia

had a learning disability, major physical illness or disability which could impact participation, or a history of brain lesion/major head trauma. The pilot study demonstrated feasibility and found significant improvements in quality of life (Churcher Clarke, Chan, Stott, Royan, \& Spector, in press). Conclusions are limited by a small sample $(n=31)$ and the absence of longterm follow-up, yet at present this is the largest and most robust pilot study on mindfulness in dementia to date in care home setting.

\section{The Mindfulness Programme Manual}

\section{Introduction}

The Mindfulness Programme aims to equip people with dementia with skills to manage psychological distress. Sessions outlined here are intended for use by clinicians who attended the MBSR or MBCT programme as participants and are also practising mindfulness meditation. Although the manual is presented in a structured format, facilitators should be flexible in intervention delivery to accommodate to the participants' preferences, cognitive and physical abilities. Facilitators may need to: increase the amount of modelling with use of simplified concrete language, more repetitions and time allocated to explain concepts, frequent guidance and reminders during meditation to address confusion (e.g. forgetting what they were doing or where they were) and to check in with participants in terms of any physical discomfort and/or distress.

\section{Intervention structure and format}

The Mindfulness Programme is a 10-session programme, delivered twice a week for an hour in a quiet room at the care home. A small group size is recommended, i.e. an average of five per group, to allow more time for participants to process their experiences. Although it is possible to deliver the intervention with one facilitator, two facilitators are recommended: one facilitator in charge of engaging the group in the goal for the session, while the other actively demonstrates techniques on an individual basis and may physically assist those who 
Mindfulness manual for people with dementia

require additional assistance. For supervision and adherence processes, recording of intervention sessions is encouraged whenever this is practical and where permission is obtained from participants. An overview of the mindfulness programme is shown in Table 1.

To facilitate learning and familiarity, the format for all sessions is standardised: the opening of each session includes: introductions of facilitators, reminder of the purpose of the group, emphasis that participation is voluntary and a brief recap of the previous session and aim of the current session. This is followed by a mindful warm-up activity and a song that is chosen collectively in the first session. The mindful warm-up activity involves every participant taking turns to hold a soft ball and spend a brief moment to pause, think and share with the group how they feel at that present moment. The rationale for the activity is to start introducing elements of mindfulness by providing participants opportunities to be in tune with and express their emotions. The song is sung just before and after the main mindfulness activities. As well as facilitating engagement, it also serves as a reminder that the mindfulness activity has started/ended.

In each session (except the first session), there are two guided mindfulness meditations and 5-10 minutes of group discussion for each practice. The group discussions include modelling by facilitators and the use of participants' language and experiences. The aim of the group discussions is to facilitate understanding of using mindfulness to explore thoughts, feelings and sensations, including pain.

The first practice is always mindful breathing. The second practice is another core mindfulness practice (either mindful movement or body scan depending on the capabilities and preferences of the group) alternating with an informal mindfulness technique incorporating a sensory element (mindful listening, seeing, smelling or touch).

In order to enhance attention and avoid pain and discomfort due to prolonged sitting there is a 5-10 minute break between the two practices for refreshments. Closing of the 
Mindfulness manual for people with dementia

session includes an optional 3-minute breathing space practice, a brief summary of the session activity, and the group song.

\section{Maintaining a mindful stance at all times}

Maintaining a mindful stance requires facilitators to have their own mindfulness practice and it means embodying the following seven attitudes of mindfulness practice: nonjudging, patience, beginner's mind, trust, non-striving, acceptance, and letting-go (KabatZinn, 2013). Each session needs to be appropriately paced according to the needs and capabilities of the participants, i.e. do not strive to work through all the session content at the cost of minimising learning opportunities.

A mindful stance also means not striving for a particular result from participants. Such a stance also encompasses being curious and embracing uncertainty. The lead facilitator can model this during group discussion, for example, in response to a participant who may wonder how they brought their attention back to their breath, 'isn't that interesting how your attention just came back, I wonder how that happens'. Facilitators will aim to be flexible and remain open to whatever arises in order to maximise opportunities for experiential learning. For instance, in a group discussion, a participant may express boredom about the preceding exercise and say that they feel like leaving the room. A facilitator might respond by acknowledging the boredom whilst also enquiring what made them engage in the exercise, despite being bored.

\section{General guidelines for facilitating the group}

During the mindful warm-up activity, sometimes participants may become distracted from the task, e.g. showing interest in the features of the ball (e.g. 'I like yellow'). The lead facilitator can acknowledge and validate participant's experience, whilst reframing this to facilitate awareness of the here-and-now (e.g. 'You are noticing the ball is yellow, and you like that colour'.) 
Mindfulness manual for people with dementia

If a participant falls asleep during a mindfulness practice, it may be helpful to do one or more of the following: Remind participants to open their eyes or adjust their sitting position (see scripts); check in with everyone in the group individually by name, e.g. 'I'd just like to check how everyone is doing. '; allow the participant to sleep and check in again during group discussion.

Group discussion aims to facilitate participants' learning by: (1) Noticing sensations (including pain), thoughts and feelings (i.e. connecting with their direct experience of the practice); (2) Discussing how they related to these experiences and made sense of them (i.e. the effects of bringing awareness); (3) Linking to mindfulness principles. The lead facilitator may use funnelling questions, i.e. start with an open question, 'How was that for you?' Use initial responses from participants to encourage further discussion. Where people are struggling with an open question, it may be useful to provide options in a closed question format, whilst always allowing for the possibility of alternative experiences, e.g., 'Some people found the breathing relaxing, some people found it boring. What about other people? Did others find it relaxing, boring, or something else?' Facilitators may also use their own experiences of the practice as a form of modelling, e.g. 'I noticed my breath becoming slower.'

The scripts provided here are only guides. Facilitators are encouraged to be flexible in the way the instructions are provided for the practices.

\section{Involving staff}

At least one care staff member is encouraged to attend the group with the main aim of providing them experience of mindfulness in order to support the participants in home practice. A secondary aim is to provide an opportunity for staff to observe participants in the intervention, for example in a reflective state, to promote personhood. Staff are welcomed to attend the sessions whenever they are available. 
Mindfulness manual for people with dementia

To facilitate appropriate support, it is strongly encouraged that staff attend a 1-hour taster session prior to commencement of the Mindfulness Programme. The session content includes: psycho-education about mindfulnesss, identifying barriers and ways to support home practice, and a 15-minute mindful breathing practice.

\section{Home practices}

Between sessions, participants are encouraged to practice a 10-minute mindful breathing and/or 3-minute breathing space meditation with staff support daily using supplied CDs. It is recommended that the practice be conducted as a group activity as it might not always be practicable for staff to support individual practice. A weekly log sheet is given to staff to monitor home practice (Figure 1). Staff can approach the facilitators to discuss any issues arising through their experience of supporting the practice.

To remind staff to support the home practice, laminated visual cues (Figure 2) are given to place at strategic locations in the care home (e.g., in common areas where staff tended to be, and at eye level).

\section{Materials}

Materials for each session used include labels for name badges, flipchart with brief reminders of each session, meditation bell (or a mobile app version), and attendance list. Any additional materials required are mentioned in the session outline itself.

\section{Overviews of all sessions}

\section{SESSION 1}

\section{Session goal: Introduction to mindfulness, mindful breathing exercise}

Additional materials: copies of a list of songs with a short verse/chorus extracted

\section{Introduction [10-15 minutes]:}

- Introductions; name labels; welcome everyone; statement of session goals

- Mindful warm-up activity: using soft ball to introduce name and feelings at the present 
Mindfulness manual for people with dementia

moment (emphasis right here right now e.g. not "two minutes ago or yesterday")

- Choosing of song to open session; give participants a list of possible options if participants do not identify a song

- Song

\section{Main activity [30 minutes]:}

- Introduction of mindfulness concepts [5 minutes]

- Introduction and practice of mindful breathing (Figure 5) [10-15 minutes]

- Group discussion [5 minutes]

\section{Closing [10-15 minutes]:}

- Introduction and practice of 3-minute breathing space (Figure 6)

- Song

- Reminder re next session; thank everyone for attending

\section{SESSION 2}

\section{Session goal: Introduction to mindful listening}

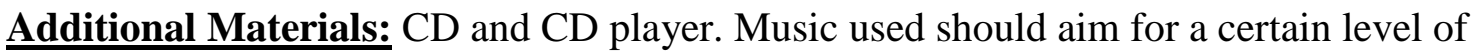
ambiguity to reduce the possibility of this exercise turning into a recreational activity. Instrumental-based music could be used, and mainstream music should be avoided.

\section{$\underline{\text { Introduction }[10 \text { minutes }]^{*}}$}

- Introductions; name labels; welcome everyone; orientation to the programme, brief recap of previous session, statement of session goals

- Mindful warm-up activity

- Song

\section{$\underline{\text { Main activity [30-35 minutes]:* }}$}

- Practice of mindful breathing (Figure 5) [10 minutes]

- Group discussion [5 minutes] 
Mindfulness manual for people with dementia

- Introduction and practice of mindful listening (Figure 7)[10 minutes]

- Group discussion [5 minutes]

\section{Closing [10-15 minutes]:*}

- Practice of 3-minute breathing space (optional if time permits; Figure 6)

- Song

- Reminder re next session; thank everyone for attending

*The session structure as shown in session 2 is repeated for the remainder of the programme.

The two main activities are highlighted in bold and italics.

\section{SESSION 3}

\section{Session goal: Body scan}

\section{Main activity [30-35 minutes]:}

- Practice of mindful breathing (Figure 5)

- Introduction and practice of body scan (Figure 8)

\section{SESSION 4}

\section{Session goal: Body awareness with mindful movement}

\section{Main activity [30-35 minutes]:}

- Practice of mindful breathing (Figure 5)

- Introduction and practice of mindful movement (Figure 9).

For sessions 5, 7 and 9, facilitators can choose any of the following as the second mindfulness practice. For sessions 6, 8 and 10, facilitators can choose either body scan (Figure 8) or mindful movement (Figure 9). The choice should be dependent on the capabilities and preferences of the group members.

(1) Mindful listening (Figure 7)

(2) Mindful seeing (Figure 10)

(3) Mindful smelling (Figure 11) 
Mindfulness manual for people with dementia

(4) Mindful touch (Figure 12)

\section{SESSION 5, 7 and/or 9}

Session goal: Connection between mind and body with focused visual component Additional materials: laminated abstract art images as focus for attention (e.g. Rothko multiform painting) or space projector (e.g. Snoezelen)

\section{Main activity [30-35 minutes]:}

- Practice of mindful breathing (Figure 5)

- Introduction and practice of mindful seeing (Figure 10)

\section{SESSION 5, 7 and/or 9}

Session goal: Body awareness with focused olfactory component Additional materials: essential oils and handkerchiefs. Add a few drops of essential oils onto the handkerchiefs for the exercise. It is important to check for allergies prior to the session.

\section{Main activity [30-35 minutes]:}

- Practice of mindful breathing (Figure 5)

- Introduction and practice of mindful smelling (Figure 11)

\section{SESSION 5, 7 and/or 9}

Session goal: Body awareness with focused tactile component

Additional materials: objects for touching (e.g. shells)

\section{Main activity [30-35 minutes]:}

- Practice of mindful breathing (Figure 5)

- Introduction and practice of mindful touch (Figure 12)

For all exercises, the script for Preparing for the exercise is the same (Figure 3). Throughout the exercises the facilitator should also remind participants (as and when appropriate (Figure 4). 
Mindfulness manual for people with dementia

\section{Discussion}

This manual provides the structure and content for an adapted mindfulness programme for people with dementia in care homes to be delivered therapists with experience in practising mindfulness meditation. Flexibility is important in implementing the programme to meet the varying needs and abilities of the group. The pilot study found promising results that this programme may be beneficial for quality of life, and it was well received with no adverse events reported. Larger clinical trials with follow-up phases are recommended to investigate the efficacy of the programme. 
Mindfulness manual for people with dementia

\section{References}

Alzheimer's Disease International (2013). World Alzheimer Report 2013. London: Alzheimer's Disease International.

Bishop, S.R., Lau, M., Shapiro, S., Carlson, L., Anderson, N.D., Carmody, J., . . Devins, G. (2004). Mindfulness: a proposed operational definition. Clinical Psychology: Science and Practice, 11, 230-241.

Chan, J. (2015). The effectiveness of mindfulness-based interventions for people with acquired cognitive impairments: a systematic review. Unpublished Clinical Psychology Doctoral Thesis. University College of London, London.

Churcher Clarke, A., Chan, J.M.Y., Stott, J., Royan, L., \& Spector, A. (in press). An adapted mindfulness intervention for people with dementia in care homes: feasibility pilot study. International Journal of Geriatric Psychiatry.

Finkel, S. (2000). Introduction to behavioural and psychological symptoms of dementia (BPSD). International Journal of Geriatric Psychiatry, 15, S2-S4.

Folstein, M., Folstein, S., \& McHugh, P. (1975). "Mini-mental state": a practical method for grading the cognitive state of patients for the clinician. Journal of Psychiatric Research, 12, 189-198.

Kabat-Zinn, J. (2013). Full catastrophe living: using the wisdom of the body and the mind to face stress, pain and illness ( $2^{\text {nd }} \mathrm{ed}$.). London: Piatkus.

Lantz, M.S., Buchalter, E.N., \& McBee, L. (1997). The Wellness Group: a novel intervention for coping with disruptive behavior among elderly nursing home residents. The Gerontologist, 37, 551-556.

Litherland, R., \& Robertson, G. (2014). Mindfulness meditation: can it make a difference? Journal of Dementia Care, 22, 31-33.

McBee, L. (2008). Mindfulness-based elder care. New York: Springer Publications.

Wells, R.E., Kerr, C. E., Wolkin, J., Dossett, M., Davis, R. B., Walsh, J. , . . \& Yeh, G. (2013a). Meditation for Adults with Mild Cognitive Impairment: A Pilot Randomized Trial. Journal of the American Geriatrics Society, 61, 642-645.

Williams, M., \& Penman, D. (2011). Mindfulness: a practice to finding peace in a frantic world. London: Piatkus. 
Table 1

Overview of the modified mindfulness programme

Session 1

Introduction to the Mindfulness Programme

Mindful warm-up activity with soft ball

Choice of group name and song

Mindfulness meditation 1: Mindful Breathing (Figure 5)

Group discussion

3-minute breathing space (Figure 6)

Song

\section{Session 2}

Introductions

Orientation to the programme and recap of previous session

Mindful warm-up activity with soft ball

Song

Mindfulness meditation 1: Mindful Breathing (Figure 5)

Group discussion

Mindfulness meditation 2: Mindfulness Listening (Figure 7)

Group discussion

3-minute breathing space (optional; Figure 6)

Song

Session 3*

Mindfulness meditation 1: Mindful Breathing (Figure 5)

Mindfulness meditation 2: Body Scan (Figure 8)

\section{Session 4*}

Mindfulness meditation 1: Mindful Breathing (Figure 5)

Mindfulness meditation 2: Mindful Movement (Figure 9)

Session 5*

Mindfulness meditation 1: Mindful Breathing (Figure 5)

Mindfulness meditation 2: Mindful Listening, Seeing, Smelling, Touch**

(Figure 7,10,11 and 12 respectively) 
Mindfulness manual for people with dementia

Session 6*

Mindfulness meditation 1: Mindful Breathing (Figure 5)

Mindfulness meditation 2: Body Scan or Mindful Movement**

(Figure 8 and 9 respectively)

Session 7*

Mindfulness meditation 1: Mindful Breathing (Figure 5)

Mindfulness meditation 2: Mindful Listening, Seeing, Smelling, Touch**

(Figure 7,10,11 and 12 respectively)

Session 8*

Mindfulness meditation 1: Mindful Breathing(Figure 5)

Mindfulness meditation 2: Body Scan or Mindful Movement***

(Figure 8 and 9 respectively)

Session 9*

Mindfulness meditation 1: Mindful Breathing (Figure 5)

Mindfulness meditation 2: Mindful Listening, Seeing, Smelling, Touch**

(Figure 7,10,11 and 12 respectively)

Session 10*

Mindfulness meditation 1: Mindful Breathing (Figure 5)

Mindfulness meditation 2: Body Scan or Mindful Movement***

(Figure 9 and 10 respectively)

* The session structure as shown in session 2 was repeated for the remainder of the programme. The two mindfulness meditations in each session are in bold type.

** Depending on capabilities and preferences of the group. 
Mindfulness manual for people with dementia

Mindfulness and dementia study - home practice log sheet

NAME OF PARTICIPANT:

WEEK COMMENCING:

Research shows that mindfulness works much better when people practice the techniques outside of sessions.

The main technique we would like people to practice every day is the 3-minute breathing space. PLEASE CIRCLE YES OR NO. People may also want to practice the breath awareness exercise (10 minutes).

However, if you practice any of the other techniques learnt during the sessions, please describe.

It is also okay if the participant has not practiced any techniques - we would really appreciate your honesty (-)

\begin{tabular}{|c|c|c|c|c|c|c|}
\hline Thursday & Friday & Saturday & Sunday & Monday & Tuesday & Wednesday \\
\hline $\begin{array}{l}\text { 3-min } \\
\text { breathing }\end{array}$ & $\begin{array}{l}\text { 3-min } \\
\text { breathing }\end{array}$ & $\begin{array}{l}\text { 3-min } \\
\text { breathing }\end{array}$ & $\begin{array}{l}\text { 3-min } \\
\text { breathing }\end{array}$ & $\begin{array}{l}\text { 3-min } \\
\text { breathing }\end{array}$ & $\begin{array}{l}\text { 3-min } \\
\text { breathing }\end{array}$ & $\begin{array}{l}\text { 3-min } \\
\text { breathing }\end{array}$ \\
\hline YES/NO & YES/NO & YES/NO & YES/NO & YES/NO & YES/NO & YES/NO \\
\hline $\begin{array}{l}\text { Breath } \\
\text { awareness }\end{array}$ & $\begin{array}{l}\text { Breath } \\
\text { awareness }\end{array}$ & $\begin{array}{l}\text { Breath } \\
\text { awareness }\end{array}$ & $\begin{array}{l}\text { Breath } \\
\text { awareness }\end{array}$ & $\begin{array}{l}\text { Breath } \\
\text { awareness }\end{array}$ & $\begin{array}{l}\text { Breath } \\
\text { awareness }\end{array}$ & $\begin{array}{l}\text { Breath } \\
\text { awareness }\end{array}$ \\
\hline YES/NO & YES/NO & YES/NO & YES/NO & YES/NO & YES/NO & YES/NO \\
\hline
\end{tabular}

Figure 1. Home practice log sheet

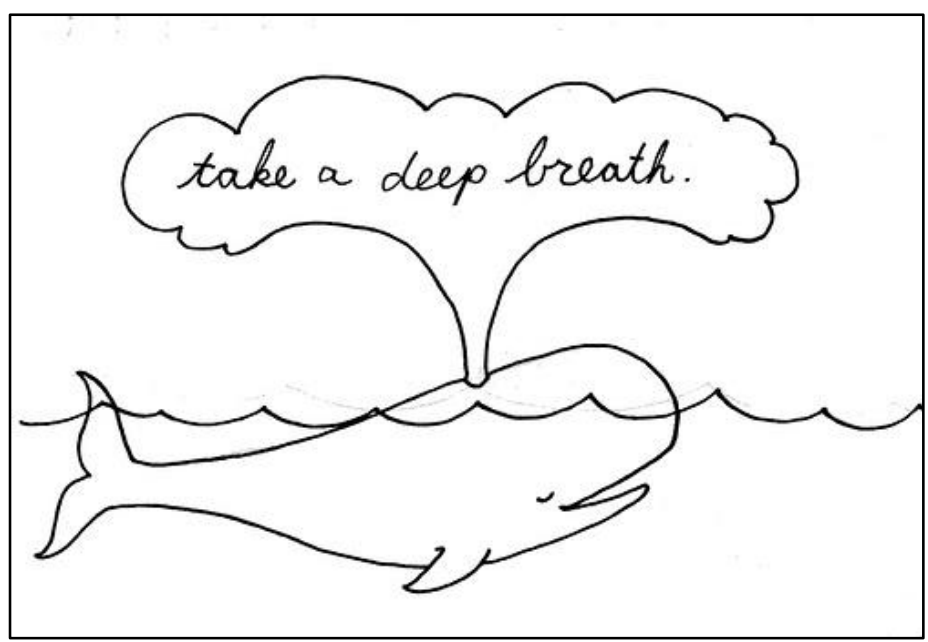

Figure 2. Laminated visual cue for care homes 
Mindfulness manual for people with dementia

First, let's prepare for the exercise.

Place your feet flat on the floor, with your legs uncrossed [DEMO].

Settle into a comfortable sitting position on your chair. Sit up as straight as you can, without hurting yourself. Place your hands gently on your lap [DEMO].

For this exercise, try to close your eyes [DEMO]*

Bring your attention to the sensations of your body in the chair. Ask yourself can you feel your feet on the floor, or can you feel your hips in the chair?

Sometimes you may notice that you lose concentration while doing the exercise. This is perfectly OK. Getting distracted happens to everyone. Our minds like to go for a walk. [REPEAT DURING EXERCISE FREQUENTLY]

* For mindful movement, mindful seeing and mindful smelling, participants would require their eyes to be opened for the exercises.

Figure 3. Preparing for the exercise

- If you notice any tension or pain, ask yourself what does it feel like? Ask yourself can you observe these sensations as they rise and fall? Come and go?

- Instead of pushing pain away, approach these sensations with curiosity and kindness as best as you can.

- The idea here is not to stay in the same sitting position until it is too painful. Please change your sitting position if you need to. Do what works for you.

- If you are starting to feel sleepy, it can help to open your eyes for a moment or change your sitting position, and gently bring your attention back to wherever we are in the exercise at that moment.

Figure 4. Reminders throughout exercises

\section{Script for sessions 1 to 10}

MINDFUL BREATHING (adapted from McBee, 2008: 181)

\section{Introduction:}

In this exercise we are going to learn to pay attention to our breath.

Preparing for the exercise (Figure 3)

Reminders throughout the exercise (Figure 4)

\section{Exercise:}

Focus your attention on your breath, let the breath be, without changing it in any way. Notice how it feels in your body to sit here and breathe. 
- Now focus your attention on your stomach. Notice the gentle rise of your stomach as you breathe in, and the gentle fall of your stomach as you breathe out.

- Imagine your stomach is like a balloon, as you breathe in the stomach stretches, and as you breathe out it becomes flatter.

- Notice how it feels in your body to sit here and breathe.

- PAUSE TO 1 MIN

- Now focus your attention on another part of your body where you can feel the breath - your chest, noticing the gentle rise of the chest as you breathe in and the gentle fall of the chest as you breathe out.

- Imagine your chest is like a balloon, as you breathe in the chest stretches, and as you breathe out it becomes flatter.

- Notice how it feels in your body to sit here and breathe.

- PAUSE TO 1 MIN

- As best as you can, try not to change or control your breath, simply let it be. Just notice and observe. Just answer in your mind what is your breath like right now? Notice if your breath is short or long. Notice if your breath is deep or shallow. Notice if your breath is fast or slow. Notice in your mind if your breath is even or uneven? Just be with your breath.

- Notice how it feels in your body to sit here and breathe.

- PAUSE TO 1 MIN

- Let's sit quietly for a while, and just simply observe your breath. If you need to move or change your posture, bring your full attention to this experience. Notice all the sensations connected with moving your body.

- Keeping your attention focused on the breath - maybe on your stomach, or your chest, noticing the gentle rise as you breathe in, and the gentle fall as you breathe out.

- Notice how it feels in your body to sit here and breathe.

- PAUSE TO 1 MIN

- As best as you can, try not to change or control your breath, simply let it be. Just notice and observe. Just answer in your mind what is your breath like right now? Notice if your breath is short or long. Notice if your breath is deep or shallow. Notice if your breath is fast or slow. Notice in your mind if your breath is even or uneven? Just be with your breath.

- Notice how it feels in your body to sit here and breathe.

- PAUSE TO 1 MIN

When you hear the sound of a bell, you may slowly awaken the body to movement, moving your fingers or toes in any way you like. As you start activity again, pay attention to the breath. The breath is always there for you. The breath can help bring you back to the present. It is like a good friend. It reminds you that you are OK just as you are. [BELL]

Figure 5. Mindful breathing 


\section{Script for Session 1}

(For remaining sessions, it is an optional practice as part of closing activity)

\section{3-MINUTE BREATHING SPACE (adapted from Kabat-Zinn, 2013:25)}

\section{Introduction:}

In this exercise we are going to learn a short breathing practice. The 3-minute breathing space is a short practice which aims to bring your attention to the present moment. The 3-minute breathing space may also help you when you experience difficult feelings, like stress or frustration.

Try practising the 3 -minute breathing space every day.

Preparing for the exercise (Figure 3)

Reminders throughout the exercise (Figure 4)

\section{Exercise:}

First Minute - Awareness:

- Bring yourself into the present moment. Ask yourself: "What is going on in me right now... What am I thinking? What are my feelings? Can I feel any sensations in my body?"

- Whatever you are experiencing, just notice it as it is - not judging it. Simply be aware of what is going on in you at this present moment.

\section{Second and Third Minute - Gathering:}

- Now direct your full attention to your breathing. Be aware of how it feels in your body each time you breathe in, and each time you breathe out.

- Notice the gentle rise of your stomach as you breathe in, and the gentle fall of your stomach as you breathe out.

- Bring your full attention to each breath, as one breath follows the other.

- Your breath can help bring your attention into the present moment.

When you hear the sound of a bell, you may open your eyes and bring your attention to the room whenever you are ready. As you start activity again, pay attention to the breath. The breath is always there for you. The breath can help bring you back to the present. It is like a good friend. It reminds you that you are OK just as you are. [BELL]

Figure 6. 3-minute breathing space 


\section{Script for session 2}

(Depending on the capabilities and preferences of the group, mindful listening may be repeated at Session 5, 7 and/or 9)

\section{MINDFUL LISTENING \\ (adapted from Kabat-Zinn, 2013: 72; Williams \& Penman, 2011: 143-145)}

\section{Introduction:}

Discussion of types of music liked/disliked by participants, link to thoughts, feelings, bodily sensations and behaviour. The sitting with music exercise will be using hearing as the main way of focusing your attention on the present moment (prompts: hear the music as it is, not listening out for certain sounds or instruments).

Preparing for the exercise (Figure 3)

Reminders throughout the exercise (Figure 4)

\section{Exercise:}

- Focus your attention on your breath. Let the breath be, without changing it in any way. Notice how it feels in your body to sit here and breathe. [PAUSE TO 1 MIN]

- Now when you are ready, allow the focus of your attention to shift from sensations in the body to hearing.

[PLAY MUSIC]. NB: Improvise script according to the choice of music. Prompt with the following lines as and when appropriate.

- When you hear the music, hear each note as it comes and goes.

- When you hear the music, hear as best you can the rise and fall of the sounds.

- There is no need to listen out for particular sounds. As best you can, pay attention to sounds from all directions as they arise.

- As best as you can, try breathing the sounds into your body as you breathe in and letting the sounds flow out again as you breathe out.

- Imagine that sounds can move in and out of your body as you breathe. Notice how that feels like in your body.

- Imagine that sounds can be felt by your very bones. Notice how this feels.

When you hear the sound of a bell, you may open your eyes and bring your attention to the room whenever you are ready. As you start activity again, pay attention to the sounds around you. Sounds may help bring you back to the present. [BELL]

Figure 7. Mindful listening 


\section{Script for session 3}

(Depending on the capabilities and preferences of the group, body scan may be repeated at Session 6,8 and/or 10)

\section{BODY SCAN WHILE SITTING (adapted from McBee, 2008: 182)}

\section{Introduction:}

The body scan is a slow, detailed awareness of body sensations. We will start from the toes and slowly work our way up to the top of the head.

Preparing for the exercise (Figure 3)

Reminders throughout the exercise (Figure 4)

\section{Exercise:}

- Focus your attention on your breath, let the breath be, without changing it in any way. Pay attention to how it feels in your body to sit here and breathe. [PAUSE TO 1 MIN].

- Let's start by bringing your attention to include your back, the lower back, middle and upper parts. You may notice areas of tension, pain, or stress in your back. Notice the sensations as you breathe in and out. If there is tension or pain, notice what it feels like. Ask yourself if you can observe the sensations as they rise and fall? Come and go? See if you can you feel the expansion and contraction of the back ribs as you breathe in and breathe out.

- Turn your attention to your stomach, your front ribs, and your chest. As best as you can, notice where you feel your breath. See if you can become aware of your internal organs, your lungs, heart, all the organs that support us every day. Simply observe your body as you sit here, breathing.

- Now, focus your attention on your arms. Bring your attention all the way down to the fingers as you breathe in and breathe out. See if you can notice any sensations: any tingling, throbbing, itching, moisture? Notice your palms, the top of your hands, and your wrists. Notice your hands at rest.

- Move your attention to your shoulders and neck, areas where you may experience tension and tightness. As best as you can, let your neck and shoulders be as they are for now as you breathe in and breathe out.

- From your neck, bring your attention to your throat, as best as you can feel your breath as it travels from your mouth or nose to your lungs.

- Bring your attention up to your head, the back of your head and the scalp area. See if you can notice any sensations, perhaps tingling, itching, warmth or coolness. Or maybe there are no sensations?

- Move your attention to your face. Start with your jaw, Notice if your teeth are clenched. Notice your teeth, your tongue, and your lips. Now focus on your cheeks, your nose, your nostrils, and the area below your nostrils. You may notice your breath, entering cool, coming out warm. Bring your attention to your eyes, the area around your eyes, your eyeballs and your eyebrows. Now move your attention to your forehead. As best as you can, simply see if you can notice any sensations on your forehead as you sit here, breathing.

- Now simply let your breath to return to normal, without controlling it in any way. Take a few more moments to notice the physical sensations you are feeling right here and now, and where 
you are feeling them. You may also want to observe feelings and thoughts that arise. Take a few moments to observe your body as a whole.

When you hear the sound of a bell, you may slowly awaken the body to movement, moving your fingers or toes in any way you like. As you start activity again, pay attention to your body. Your body may help bring you back to the present. [BELL].

Figure 8. Body scan

\section{Script for session 4}

(Depending on the capabilities and preferences of the group, mindful movement may be repeated at Session 6, 8 and/or 10)

\section{MINDFUL MOVEMENT WHILE SITTING (adapted from Williams \& Penman, p.119-122; McBee, p.102)}

\section{Introduction:}

The mindful movement while sitting exercise will be practising paying attention to our body while we do some gentle stretching.

Highlight that the movements should be done slowly and mindfully by paying attention to the parts of the body and the sensations, and do what feels right.

\section{Preparing for the exercise (Figure 3)}

Reminders throughout the exercise (Figure 4)

\section{Throughout the exercise the facilitator should also remind participants (as and when} appropriate):

- Do not forget to breathe. Just breathe in and breathe out freely at your own pace.

- Do only what feels right to you.

- If you find that you cannot do the movement. That's okay. Simply pay attention to your breathing and imagine that you are doing [name the pose] with us.

- Do it very slowly, paying attention to your [name part of body].

Facilitator should explain each pose, demonstrate, and then ask the participants to do it. Offer hands-on assistance as necessary. Remember to offer lots of encouragement and praise.

\section{Exercise:}

- Focus your attention on your breath, let the breath be, without changing it in any way. Notice how it feels in your body to sit here and breathe [PAUSE TO 1 MIN].

- Now when you are ready, take a breath and very slowly raise your hands in front of you and very slowly wriggle your fingers. If you cannot use one hand, simply stretch the other hand. If you cannot move both hands at all, simply pay attention to your breathing and imagine that you are wriggling your fingers with us.

- Take some time to feel the sensations of the muscles and joints in your fingers as you wriggle your fingers very slowly.

- When you are ready, slowly - very slowly- as you breathe out, allow your hands to come to rest. Lower them slowly, feeling the changing sensations as your hands slowly come to rest. 
- Now gently close your eyes for a moment, and pay attention to your breath and the sensations throughout your body. Perhaps notice the after-effects of doing the stretch [PAUSE TO 1 MIN].

- Now very slowly raise your arms out in front of you and stretch. If you cannot use one arm, simply stretch the other arm. If you cannot move both arms at all, simply pay attention to your breathing and imagine that you are stretching with us.

- As you are stretching your arms, take some time to feel the sensations of stretch in the muscles and joints in your body. As you slowly raise your arms, pay attention to your arms. If you notice any tension or pain, ask yourself what does it feel like? Ask yourself can you observe these sensations as they rise and fall? Come and go?

- When you are ready, slowly - very slowly- as you breathe out, allow your arms to come back down. Lower them slowly, feeling the changing sensations as they come down. Perhaps you might also feel the clothes moving on the surface of your skin. Pay attention to the sensations as your arms slowly come back to rest.

- Now gently close your eyes for a moment, and pay attention to your breath and the sensations and feelings throughout your body. Perhaps notice the after-effects of doing the stretch [PAUSE TO 1 MIN].

- Slowly open your eyes. Take a breath and very slowly open your arms wide and stretch. As you stretch very slowly, see if you can pay attention to the sensations in the muscles as the muscles work to lift the arms. Pay attention to the muscles as they help the arms to stretch.

- Now we are going to fold our bodies, just like flowers closing. As you breathe out, allow your arms very slowly to hug yourself. As your arms, very slowly, start to hug yourself, see if you can notice any changing sensations in your body.

- Now gently close your eyes for a moment, and pay attention to your breath and the sensations and feelings throughout your body. Perhaps noticing the after-effects of doing the stretch.

When you hear the sound of a bell, you may open your eyes and bring your attention to the room whenever you are ready. As you start activity again, pay attention to the movements of your body. Noticing the sensations of movement in your body may help bring you back to the present moment. [BELL]

Figure 9. Mindful movement

\section{Script for session 5,7 and/or 9}

\section{MINDFUL SEEING}

\section{Introduction:}

Discussion of what participants like to look at in their environment, e.g. what they find pleasant/unpleasant.

Pass around laminated images as focus for attention [abstract art] OR explain that there will be some images that will be projected on the wall [space projector]. Emphasise that the images are abstract, and the idea is not trying to guess what the images are. Simply be curious when looking at the images. 
The sitting with what we can see exercise will be using sight as the main way of focusing your attention on the present moment.

\section{Preparing for the exercise (Figure 3)}

Reminders throughout the exercise (Figure 4)

\section{Exercise:}

- Focus your attention on your breath, let the breath be, without changing it in any way. Notice how it feels in your body to sit here and breathe. [PAUSE TO 1 MIN].

- Now when you are ready, allow the focus of your attention to shift from sensations in the body to what you can see in the image you are holding.

- Really pay attention to the lines, colours and shapes.

- Allow your attention to settle on one part of the image. Ask yourself what happens to the quality of the colour, shape and texture as you move your eyes across this part. Just answer in your mind what is the colour like? Notice if its tone becomes duller or brighter? Notice what happens at the point where shape becomes another. Notice the surface of the colour, the areas where it seems to become thicker and thinner? Notice if there is any variation in the roughness or smoothness of the surface.

- As best as you can, simply see what is here to be seen, without judging it.

- You may find that you are thinking about the image looks like. As best you can, see if you can let go of those ideas and bring your attention to the qualities of colour, shape and texture as you focus your attention on the image.

- Notice what it feels like in your body, right here and now, while you are looking at the image. And if there is a lack of any sensations, simply notice how that feels as best as you can. [PAUSE TO 1 MIN].

When you hear the sound of a bell, you may bring your attention to the room whenever you are ready. As you start activity again, pay attention to what you can see around you. Noticing what you can see may help bring you back to the present moment. [BELL]

Figure 10. Mindful seeing

\section{Script for session 5,7 and/or 9}

\section{MINDFUL SMELLING}

\section{Introduction:}

Discussion of types of smell liked/disliked by participants. Let participants choose a scent for this exercise. The sitting with smell exercise will be using smelling as the main way of focusing your attention on the present moment.

\section{Preparing for the exercise (Figure 3)}

Reminders throughout the exercise (Figure 4)

\section{Exercise:}

- Focus your attention on your breath, let the breath be, without changing it in any way. Notice how it feels in your body to sit here and breathe. [PAUSE TO 1 MIN]. 
- Now when you are ready, allow the focus of your attention to shift from sensations in the body to smelling.

- Bring the handkerchief up towards your face and see if you can smell it. Be open to the smells as they arise.

- As best as you can, simply smell what is here to be smelt, without judging or thinking about what you are smelling. Perhaps there is a lack of smell.

- You may find that you are thinking about the smells. You might wonder what the smells are. You might be thinking of a time in the past when you have smelt the smell before.

- Bring your attention to the smell of the object, as if you are smelling this smell for the very first time.

- Notice what it feels like in your body, right here and now, while you are smelling the handkerchief. And if there is a lack of smell, simply notice how that feels in your body as best as you can. [PAUSE TO $1 \mathrm{MIN}$ ].

When you hear the sound of a bell, you may bring your attention to the room whenever you are ready. As you start activity again, pay attention to what you can smell around you. Noticing what you can smell can help bring you back to the present. [BELL]

Figure 11. Mindful smelling

\section{Script for session 5,7 and/or 9}

\section{MINDFUL TOUCH}

\section{Introduction:}

Discussion of types of textures liked/disliked by participants (example prompts: animals - cats, snakes; places - sand, pebbles). Let participants choose a material for this exercise. The sitting with touch exercise will be using touch as the main way of focusing your attention on the present moment.

\section{Preparing for the exercise (Figure 3)}

Reminders throughout the exercise (Figure 4)

\section{Exercise:}

NB: participants may swap objects for this exercise if time permits.

- Focus your attention on your breath, let the breath be, without changing it in any way. Notice how it feels in your body to sit here and breathe. [PAUSE TO 1 MIN].

- Now when you are ready, allow the focus of your attention to shift from sensations in the body to touching the object.

- Hold the object in your hand and run your fingers over its surface. Really pay attention to where your fingers make contact with the surface.

- As you move your fingers across the object, simply notice if there are any changes in its texture. However, small these may be. Perhaps the object feels the same all over. Ask yourself 
Mindfulness manual for people with dementia

if the sensations in your fingers change as you move from the object's centre to its edges.

- As best as you can, simply touch what is here to be touched, without judging or thinking about what you are touching.

- You may find that you are thinking about the textures you can feel. You might wonder what the object is or where it has come from. You might be thinking of a time in the past when you have come into contact with this texture before.

- Bring your attention to the feel of the object, as if you are touching the object for the very first time.

- Notice what it feels like in your body, right here and now, while you are touching the object. [PAUSE TO 1 MIN].

When you hear the sound of a bell, you may bring your attention to the room whenever you are ready. As you start activity again, see if you can noticing what you touch. This may help bring you back to the present. [BELL]

Figure 12. Mindful touch 


\section{Author Biographies}

Joanne Chan is a Clinical Psychologist at the Barnet Mental Health Services for Older People, UK. She completed her doctorate training in clinical psychology at University College London. Her clinical and research interests include psychosocial interventions in dementia care, and assessment and rehabilitation of acquired brain injury.

Anna Churcher Clarke is a Clinical Psychologist working with children, young people and their families at the Tavistock Gender Identity Development Service. Her research interests include psychosocial interventions in dementia care; cross-cultural mental health and illness, and identity formation including diverse gender identities and sexualities.

Lindsay Royan works in North East London NHS Foundation Trust as a Clinical Psychologist in dementia. She has a long-standing interest in Mindfulness and has trained in MBCT. She also completed a training with Breathworks. Lindsay has worked with Age UK, Alzheimer's Society and Age Exchange on various projects including training courses.

Joshua Stott is a Senior Clinical Tutor on The Doctorate in Clinical Psychology at University College London. He is also the holder of a research fellowship with the Alzheimer's Society. He has an interest in psychosocial interventions in dementia, particularly those aimed at ameliorating psychological distress.

Aimee Spector is Reader in Clinical Psychology at University College London. Her research primarily focuses on the development and evaluation of non-pharmacological interventions for people with dementia. 